\title{
ПРОБЛЕМЫ СОХРАНЕНИЯ И РАЗВИТИЯ ЯЗЫКА МАЛОЧИСЛЕННОГО НАРОДА АБАЗИН*
}

\begin{abstract}
В статье рассмотрена проблема сохранения родного языка абазинами - законодательно признанным малочисленным народом РФ. Угроза ассимиляции и потери языка активизировали деятельность абазинских общественных организаиий в этнокультурной сфере. Приоритетныли стали проблемы сохранения абазинского языка и сближения двух родственных народов - абазин и абхазов, в том числе проживающих диаспорно в других странах. По инициативе и при поддержке общественников реализуются многочисленные проекты, направленные на сохранение и развитие абазинской традиционной культуры, планируется создание единого абазино-абхазского алфавита. Результаты проводимых в Карачаево-Черкесской Республике в течение ряда лет сочиологических опросов, позволили выявить достаточно высокий уровень владения абазинским языком, в том числе, среди молодежи. Сохраняется запрос на изучение родного языка. В то же время тревожной тенденцией является отсутствие интереса кего изучению частью опрошенных. Государственная языковая политика, меры, предпринимаемые общественниками, а также достаточно высокий уровень начионального самосознания населения в целом позволяют прогнозировать сохранность и развитие абазинского языка в ближайшем будущем.
\end{abstract}

Ключевые слова: абазинский язык, малочисленный народ, этническая идентичность, этнокультурные проблемы

Ссылка при цитировании: Щербина Е.А., Кубанова Л.В. Проблемы сохранения и развития языка малочисленного народа абазин // Вестник антропологии, 2021. № 2. C. 355-364.

Сфера межнациональных отношений находится в центре внимания органов власти и управления, как на федеральном, так и региональном уровнях. Решение этнонациональных проблем в контексте и в интересах упрочения единства российской гражданской нации является важнейшей задачей власти и гражданского общества. В настоящее время в России проводится масштабная экспертная, консультативная,

Щербина Елена Анатольевна - к. полит. н., доцент по специальности, заместитель директора, Карачаево-Черкесский институт гуманитарных исследований при Правительстве КЧР (369006 Черкесск, ул. Горького, д. 1, корп. А). Эл. почта: adenas@list.ru

Кубанова Лиана Владимировна - к. полит. н., ведущий научный сотрудник, Карачаево-Черкесский институт гуманитарных исследований при Правительстве КЧР (369006 Черкесск, ул. Горького, д.1, корп. А). Эл. почта: lianakubanova@mail.ru

* Статья подготовлена в рамках научного проекта №17-29-09152 «Русский язык, языки народов России и российская идентичность: антропологические подходы к изучению языковой ситуации и этнокультурной политики» 
практическая работа по реализации государственной национальной политики. Принятые абсолютным большинством граждан изменения закрепили в Конституции РФ ключевые ориентиры государственной национальной политики. Это укрепление единства народов России, обеспечение межнационального согласия, сбережение этнокультурного и языкового многообразия. Ведется активная работа по нормативному обеспечению реализации языковой политики, в частности, планируется принятие законопроекта о внесении изменений в Закон «О языках народов Российской Федерации», с целью создания необходимых условий для дальнейшего сохранения и развития родных языков (Стенограмма 2021).

Отдельно учитываются проблемы коренных малочисленных народов России, продолжается работа по сохранению их самобытности, языка и культуры, а их интересы учтены во многих федеральных нормативно-правовых документах, в том числе в Стратегии государственной национальной политики РФ до 2025 года. Совершенствуется законодательная база по вопросам реализации прав коренных малочисленных народов России.

Абазины (самоназвание абаза) - один из автохтонных народов Кавказа, законодательно признанный коренным малочисленным народом. По данным переписи 2010 г. в Российской Федерации проживают 43341 абазин. Наибольшая часть из них живет в Карачаево-Черкесской Республике (36 919 чел.). Абазины являются четвертым по численности народом в республике (всего 7,8\% от общей численности населения КЧР). Реальной угрозой для абазин является ассимиляция с другими, более крупными этносами. Одна из основных задач абазин - сохранение в едином культурном пространстве республики и страны многообразия самобытности этнического меньшинства.

Законодательство о гарантиях прав народа абазин основывается на соответствующих нормах Конституции Российской Федерации, Конституции Карачаево-Черкесской Республики, признанных Российской Федерацией нормах международного права и состоит из Федерального закона «О гарантиях прав коренных малочисленных народов Российской Федерации» (Федеральный закон 1999), а также Закона Карачаево-Черкесской Республики от 12 ноября 2001 года № 27-Р3 «О гарантиях прав коренного малочисленного народа абазин в Карачаево-Черкесской Республике» (Закон КЧР 2001).

Согласно статьи 11 Конституции Карачаево-Черкесской Республики, абазинский язык, наряду с карачаевским, ногайским, русским и черкесским, является государственным языком (Конституция КЧР 1996). Таким образом, закреплен статус этого народа как одного из субъектообразующих в республике. Языковая политика в КЧР базируется на законе КЧР от 14.06.1996 г. № 104-ХХІІ (ред. от 28.12.2001г.) «О языках народов Карачаево-Черкесской Республики» (Закон КЧР 1996). Настоящий закон направлен на создание условий для сохранения, равноправного и самобытного развития языков народов КЧР. В статье 1 данного закона закреплен статус пяти государственных языков, в том числе и абазинского.

Абазинский язык изучается в начальной (1-4 кл.), средней (5-11кл.) и высшей (бакалавриат, магистратура) школе, где готовятся специалисты - преподаватели родного языка и литературы, журналисты, а также на уровне послевузовского образования (аспирантура, переподготовка, различные формы повышения квалификации). На абазинском языке издаются республиканская газета «Абазашта», журнал «Марамыз» («Созвездие»); научная и учебно-методическая литература; произведения, 
относящиеся к поэтическим жанрам, рассказы и повести, детская художественная литература, фольклорные произведения. Ведутся передачи на радио и телевидении, работают два театра (государственный и народный).

В последние годы активизировалась деятельность абазинских общественных организаций в этнокультурной сфере. Приоритетными стали проблемы сохранения абазинского языка, сближение двух родственных народов - абазин и абхазов, в том числе проживающих диаспорно в других странах - Турции, Иордании, Египте. Вопросами их объединения занимается Всемирный абхазо-абазинский конгресс (ВААК), который главным целями ставит сохранение народа, одним из основных факторов для этого является сохранение общего абазино-абхазского языка. В местах, где создаются советы местных и региональных отделений ВААК, открываются кружки по изучению родного языка и национальных танцев, например, в Санкт-Петербурге и Москве. Инновационной формой изучения этих языков стал запуск онлайн-проекта, в основе которого видеоуроки с простыми фразами на абазинском и абхазском языках, для абазино-абхазской диаспоры, проживающей в разных странах мира (Новые возможности 2020). Проект направлен не только на сохранение языков, но, на наш взгляд, имеет и другую цель - объединение народа абаза.

Довольно эффективно в сфере языковой политики показала себя модель совместной работы общественных объединений, меценатов и государства. Свидетельством тому является деятельность наиболее активной общественной организации - международного объединения по развитию абазино-абхазского этноса «Алашара», функционирующей с 2011 года. Все активные абазинские общественные организации в 2016 году были объединены в Ассоциацию общественных объединений по сохранению культурного наследия и социально-экономическому развитию абазинского народа «Апсадгьыл» («Родина»), что позволяет более эффективно решать актуальные для народа проблемы.

Среди важнейших этнокультурных проблем абазинские общественники декларируют следующие: сокращение числа абазин, особенно, детей, владеющих абазинским языком; падение интереса к родному языку и этнокультуре в абазинских семьях; декларативный характер закона о малочисленном народе в КЧР; ассимиляция абазин, проживающих за пределами республики; разобщенность специалистов абазинского языка, работающих в разных сферах; нехватка учебников абазинского языка и квалифицированных специалистов во всех сферах функционирования абазинского языка; нехватка абитуриентов на отделениях абазинского языка в Карачаево-Черкесском педагогическом колледже и Карачаево-Черкесском государственном университете.

За время своего существования АНО «Алашара» помогло осуществлению многих проектов, направленных на сохранение и развитие абазинской традиционной культуры. Ежегодно проводится День культуры народа Абаза (в День государственного флага Абхазии) в рамках культурно-спортивного фестиваля «Абаза»; научно-практические семинары учителей абазинского языка и литературы «Клычевские чтения», научные конференции «Табуловские чтения» с участием ученых и учителей республики. АНО «Алашара» дважды становилось обладателем Президентских грантов: в 2014 году за издание книги к 70-летнему юбилею Победы в Великой Отечественной войне «Подвиги героев Абазашты», в 2019 году в номинации «Поддержка проектов в области науки, образования и просвещения» на проведение Фестиваля абазинского языка и литературы. Фестиваль стал ежегодным и проводится АНО «Алашара» с Ка- 
рачаево-Черкесским государственным университетом совместно с Министерством образования и науки КЧР и администрацией Абазинского муниципального района. Использование средств Президентского гранта позволило расширить масштабы его проведения. В рамках Фестиваля организовываются мероприятия, направленные на работу, как с учащейся молодежью, так и с научной и педагогической общественностью: конкурсы на знание абазинского языка и литературы, научно-практические конференции, мастер-классы по организации и проведению уроков абазинского языка и литературы в сельской школе и др. (Состоялась встреча 2019). В планах - проведение в рамках Фестиваля «Дня абазинской письменности».

С 2015 года предметом дискурса, инициированного «Алашарой», стали вопросы, касающиеся изучения языков и культуры абазин и абхазов, в том числе унификации алфавита, что вызвало неоднозначную оценку со стороны некоторых ученых. Споры касались того, на какой основе необходимо составлять алфавит - кириллице или латинице. Сторонники создания алфавита на латинице одним из аргументов приводят тот факт, что именно ею пользуются сотни тысяч представителей диаспоры, проживающие в разных странах (Дасания 2020). Есть ученые, которые считают, что, хотя и абазинский, и абхазский алфавиты основаны на русской графической основе, принцип их построения совсем иной. Поэтому при создании единого алфавита необходимо либо менять все коренным образом, либо переходить на один из алфавитов, абазинский или абхазский, либо создать новый алфавит (Чирикба 2020)

Абазинский язык с точки зрения фонетики считается одним из самых сложных в мире, поэтому вызывает у ученых большой интерес. Алфавит абазинского языка насчитывает 71 букву, из которых только 6 гласных. Фонетическое разнообразие абазинской речи складывается из обилия свистящих и шипящих звуков, а также их переходных форм. В 2017 году в Карачаево-Черкесии была проведена исследовательская экспедиция по изучению абазинского языка, в которой приняла участие группа ведущих лингвистов и филологов, специализирующихся на исследовании типологии кавказских языков учебно-научного центра лингвистической типологии Института лингвистики Российского государственного гуманитарного университета (РГГУ) и Российской академии наук (РАН).

В 2015 году была разработана и начала реализовываться долгосрочная программа «Абазины и абхазы: сохранение и развитие языков, полевые исследования и архивные материалы», которая предусматривала конкретные задачи и пути их решения на три года и перспективные задачи на период до десяти лет. В 2019 году была разработана программа сохранения и развития абхазо-абазинского языка. В 2021 году Всемирный абхазо-абазинский конгресс совместно с АНО «Алашара» утвердили ее дополненный вариант, который включает в себя такие мероприятия, как подготовка и переподготовка педагогических кадров, подготовка научных и научно-педагогических кадров, разработка и издание учебной литературы, популяризация знаний по абазинскому языку и литературе, разработка абхазо-абазинского алфавита на основе кириллицы и его апробация на экспериментальной площадке с учетом возможности его использования в Карачаево-Черкесии, Абхазии, Турции и других странах, где компактно проживают абазины и абхазы. В числе приоритетных задач, помимо издания большого перечня методических, справочных материалов и словарей, планируется создание электронных баз данных, в первую очередь - электронного корпуса абазинского и абхазского языков. 
Проведенные в регионе на протяжении ряда лет социологические опросы по изучению этнокультурной, в том числе, языковой ситуации в рамках реализации федеральных проектов ${ }^{1}$, позволили оценить социальные установки и личностные мотивы молодежи, взрослого населения, в отношении абазинского языка, его сохранения, применения в семье, обучения и развития. Так как опросы проводились в режиме мониторинга, то есть по единой методике в течение нескольких лет, сравнительный анализ результатов в динамике позволил представить установки, мнения, суждения, которые можно считать модальными и устоявшимися.

Данные массовых социологических опросов ${ }^{2}$ показывают, что для абазин родной язык - это в первую очередь язык семьи, родственников, так считают $41 \%$ опрошенных. Почти треть опрошенных (27\%) определяет родной язык как язык народа, национальности, т.е. как идентификатор этнической идентичности, пятая часть (18\%) считает, что родной язык тот, на котором постоянно общаются, 9\% опрошенных определили, что родным является язык, на котором человек думает.

Большинство абазин использует родной язык при общении (76,5\%). При этом четвертая часть $(23,5 \%)$ не общается на абазинском языке. Среди причин опрошенные назвали следующие:

- не знаю родной язык (мало знаю родной язык) - 17,6\%;

- окружающие не знают моего языка $-20,6 \%$;

- испытываю стеснение при использовании родного языка $-5,9 \%$.

Исследование показало, что в портфеле идентичностей абазин на первом месте общегражданская идентичность, на втором месте - этническая, на третьем - реги-

${ }^{1}$ Социологические опросы были проведены в рамках Проекта № 3437 Распределенного научного центра межнациональных и межконфессиональных проблем Министерства образования и науки РФ «Мониторинг межнациональных отношений и религиозной ситуации. Исследование проблем зарубежных северокавказских диаспор в аспекте обеспечения стабильности и безопасности России в СКФО. Анализ проблем этнокультурного и исторического образования. Анализ языковой политики в регионах СКФО»; Проекта 8.4504.2017 Распределенного научного центра межнациональных и межконфессиональных проблем Министерства образования и науки РФ «Мониторинг этноконфессиональной ситуации в полиэтничных регионах Российской Федерации на основе модели Распределенного научного центра межнациональных и религиозных проблем, анализ гуманитарного предметно-дисциплинарного цикла в школах и вузах в аспекте формирования российской идентичности, воспитания гражданской ответственности и солидарности в регионах в регионах СКФО (Ставропольский край, Республика Северная Осетия-Алания, Кабардино-Балкарская Республика и Карачаево-Черкесская Республика)»; Проекта 12883.2018/12.3 «Мониторинг этноконфессиональной ситуации в полиэтничных регионах РФ на основе модели Распределенного научного центра межнациональных и религиозных проблем в регионах СКФО (Ставропольский край, Республика Северная ОсетияАлания, Кабардино-Балкарская Республика и Карачаево-Черкесская Республика); анализ конфликтного и интеграционного потенциала межэтнических и миграционных отношений в регионах СКФО (Ставропольский край, Республика Северная Осетия-Алания, КабардиноБалкарская Республика и Карачаево-Черкесская Республика)»; Проекта РФФИ №17-29-09152 "Русский язык, языки народов России и российская идентичность: антропологические подходы к изучению языковой ситуации и этнокультурной политики».

${ }^{2}$ Социологический опрос проведен в рамках «Мониторинга этноконфессиональной и миграционной ситуации на основе модели Распределенного научного центра межнациональных и религиозных проблем накануне Всероссийской переписи населения в регионах Северо-Кавказского федерального округа (Ставропольский край, Республика Северная Осетия-Алания, Кабардино-Балкарская Республика и Карачаево-Черкесская Республика)». 
ональная. При ответе на вопрос: «Как Вас должны воспринимать окружающие в повседневной жизни, - как гражданина России, или как представителя отдельной национальности, или как жителя определенного региона?» ответы распределились следующим образом:

- $\quad$ как гражданина страны - 70,6\%;

- $\quad$ как представителя отдельной национальности - 38,2\%;

- $\quad$ как жителя определенного региона $-5,9 \%$.

Главную роль в формировании и передаче ценностей, норм, представлений, характерных для конкретной культуры, играет семья. Социологические опросы позволили изучить мнение родителей учащихся (абазин) о необходимости этнокультурного образования и изучения родного языка. Были опрошены родители учащихся, обучающихся на разных ступенях образования: начальная школа (1-4 классы), средняя ступень (5-9 классы) и старшая ступень (10-11 классы).

Результаты исследования свидетельствуют о том, что большинство родителей заинтересованы в том, чтобы их дети изучали абазинский язык $(83,3 \%$ респондентов). В тоже время часть из них не побуждает своих детей к занятиям национальным языком. Большинство родителей школьников - представители среднего поколения (от 30 до 50 лет), имеющие высшее или средне-специальное образование, проживающие в регионе с рождения, и относящие себя, в основном, к одной национальности. Такая ситуация вызывает обеспокоенность общественников, которые видят в сложившейся ситуации угрозу потери родного языка. Поэтому ситуация с сохранением абазинского языка рассматривается как этническая проблема, именно поэтому разрабатываются специальные долгосрочные программы по системному изменению языковой ситуации.

В ходе опроса изучалось мнение родителей о том, какое обучение национальному языку они бы выбрали для своих детей. Были получены следующие ответы:

- стандартное изучение национального языка - 55,6\%;

- углубленное или дополнительное изучение национального языка $-27,8 \%$;

- обучение без национального языка - 11,1\%;

- только общее знакомство с национальным языком - 5,6\%;

- обучение на национальном языке - $0 \%$.

Таким образом, большинство из них склоняется к стандартному изучению абазинского языка, только четвертая часть респондентов ориентирована на то, чтобы их дети занимались изучением абазинского языка углубленно. Тревожными данными является желание $11,1 \%$ опрошенных вообще не изучать родной язык. При этом национальная интеллигенция прилагает значительные усилия для пропаганды родных языков, на государственном уровне ставит вопросы расширения сферы их применимости, способствует распространению книжной продукции, художественных фильмов и мультфильмов для детей на абазинском языке.

Среди специалистов, преподающих абазинский язык, существует мнение, что дети, владеющие с рождения абазинским языком, теряют речевые навыки в дошкольных учреждениях, особенно в полиэтничных коллективах, и на общеобразовательной ступени обучения сложнее его усваивают. В КЧР проводятся экспериментальные методы обучения абазинскому языку в дошкольных учреждениях как в мононациональной, так и в полиэтничной среде. По инициативе и поддержке АНО «Алашара» были разработаны учебно-методические комплексы по абазинскому языку для че- 
тырех возрастных групп детских садов, которые рекомендованы Министерством образования и науки КЧР для использования в ДОУ абазинских населенных пунктов. Особый интерес представляют результаты, полученные в ходе применения этих методических комплексов в иноэтничной языковой среде. Подобный эксперимент был проведен в одном из сельских детских садов Карачаевского муниципального района. Дети различных национальностей проявили интерес к изучению абазинского языка и достигли хороших результатов в ходе его изучения. Видеозанятия с детьми, изъявившими желание изучать абазинский язык в игровой форме, доступны в сети Интернет. В одном из дошкольных образовательных учреждений республиканской столицы Карачаево-Черкесии организованы курсы абазинского языка в формате дополнительного познавательно-речевого кружка.

Результаты опросов учащейся молодежи коррелируют с ответами более старшего поколения. Пятая часть опрошенных абазин (22,9\%) отметили национальную принадлежность к двум народам. Это обусловлено тем, что в республике часты межнациональные браки, особенно между абазинами и черкесами, и дети указывают свою национальность по этнической принадлежности как отца, так и матери. Учащиеся средних общеобразовательных и высших учебных заведений ${ }^{1}(76,7 \%)$ в семье или при общении с друзьями и знакомыми используют родной язык. Молодые люди понимают необходимость изучения родных языков. Компаративный анализ результатов опросов в динамике показывает увеличение числа таких молодых людей. Можно предположить, что одним из побуждающих факторов является работа, проводимая общественниками по популяризации абазинского языка.

Среди причин, по которым молодые люди не общаются с окружающими на родном языке, были названы следующие:

- не знаю родной язык (мало знаю родной язык) - $10 \%$;

- окружающие не знают моего языка - 20\%;

- испытываю стеснение при использовании родного языка $-3,3 \%$.

В ходе опросов была выявлена еще одна закономерность, которая связана с восприятием языка молодыми людьми. Так же, как их родители, молодежь воспринимает владение родным языком, в первую очередь, как идентификатор этнической идентичности: «для того, чтобы чувствовать принадлежность к своему народу». Также выделился второй аспект, связанный с определенным проективным отношением к своей будущей профессиональной деятельности. Молодые люди связывают знание родного языка с возможностью получения специальных навыков и умений, которые могут пригодиться в воспитательной и образовательной деятельности, в сфере туризма и услуг, на радио и телевидении. То есть они видят перспективы, связанные с владением родными языками, и их практическую применимость.

Абазинская молодежь демонстрирует высокий уровень гражданской идентичности (выше, чем у людей среднего и старшего возраста). При ответе на вопрос: «Как

1 Социологический опрос был проведен в рамках проекта Распределенного научного центра межнациональных и межконфессиональных проблем Министерства образования и науки РФ: Мониторинг этноконфессиональной ситуации в полиэтничных регионах Российской Федерации на основе модели Распределенного научного центра межнациональных и религиозных проблем, анализ гуманитарного предметно-дисциплинарного цикла в школах и вузах в аспекте формирования российской идентичности, воспитания гражданской ответственности и солидарности в регионах в регионах Северо-Кавказского федерального округа (Ставропольский край, Республика Северная Осетия-Алания, Кабардино-Балкарская Республика и Карачаево-Черкесская Республика) 
Вас должны воспринимать окружающие в повседневной жизни, как гражданина России или как представителя отдельной национальности, или как жителя определенного региона?» подавляющее большинство на первое место поставили гражданскую идентичность (76,7\% опрошенных). Как представителя отдельной национальности себя идентифицируют $23,3 \%$ респондентов, региональная идентичность преобладает у 6,7\% молодых людей. По результатам опроса можно говорить о четко фиксируемой общероссийской гражданской идентичности у большинства абазин. Эти показатели коррелируют с результатами других опросов, в которых гражданская идентичность становится основной в портфеле идентичностей абазин, на втором месте - этническая идентичность.

Важно, что 88,2\% опрошенных абазин не планируют переезд в другой регион, страну на длительный срок или на постоянное жительство, то есть связывают свое будущее с регионом, в котором проживают. Десятая часть опрошенных $(11,8 \%)$ респондентов затруднились с ответом, то есть пока сомневаются. Все это свидетельствует о том, что у абазин достаточно высок уровень национального самосознания и им свойственно чувство патриотизма, любви к малой Родине.

В условиях повсеместной глобализации возрастает угроза утраты исторически сложившегося многообразия этнических культур, особенно малочисленных народов. Язык - наиважнейший аттрактор этнокультурной идентичности. Он выполняет системообразующую роль в сохранении национальной культуры и препятствует процессам ассимиляции, аккультурации этноса как культурно-языкового сообщества. Потеря родного языка для малочисленного народа, как таковая означает потерю самого этноса. Сохранение, знание родного языка, уважительное отношение к нему - это путь к сохранению национальной идентичности, уважению и любви к истории и культуре своего народа.

Учитывая достаточно высокий уровень владения абазинским языком, в том числе среди молодежи, интенсивность его использования в неофициальных сферах общения, государственную политику, направленную на поддержку функционирования языка в официальных сферах общения, высокий уровень национального самосознания в целом, можно утверждать, что степень витальности абазинского языка достаточно высока, и прогнозировать стабильность его использования в обозримом будущем.

\section{Источники и материалы}

Дасания 2020 - Дасания Д. К вопросу о создании абхазо-абазинского алфавита на основе латиницы. // Яндекс Дзен (Электронный ресурс). 23.05.2020. Доступ: https://zen.yandex. $\mathrm{ru} / \mathrm{media} / \mathrm{id} / 5 \mathrm{e} 0 \mathrm{ed} 79 \mathrm{a} 5 \mathrm{~d} 636200 \mathrm{~b} 185 \mathrm{ebb} / \mathrm{k}$-voprosu-o-sozdanii-abhazoabazin skogo-alfavitana-osnove-latinicy-5ec978dea3811a33d94a24df (дата обращения: 23.05.2020).

Закон КЧР 1996 - Закон Карачаево-Черкесской Республики от 14 июня 1996 г. N 104-XXII «O языках народов Карачаево-Черкесской Республики» (с изменениями от 03 ноября 2020 года N 77-Р328) // Электронный фонд правовых и нормативно-технических документов (Электронный ресурс). Доступ: http://docs.cntd.ru/document/802053301 (дата обращения 10.11.2020).

Закон КЧР 2001 - Закон Карачаево-Черкесской Республики от 12 ноября 2001 г. N 27-Р3 «О гарантиях прав коренного малочисленного народа абазин в Карачаево-Черкесской Республике» (с изменениями от 30.11.2020 N 90-Р3) // Электронный фонд правовых и нормативно-технических документов (Электронный ресурс). Доступ: http://docs.cntd.ru/ document/802053275 (дата обращения 10.12.2020). 
Конституция 1996 - Конституция Карачаево-Черкесской Республики // Электронный фонд правовых и нормативно-технических документов (Электронный ресурс). Доступ: https:// docs.cntd.ru/document/720705884 (дата обращения 01.05.2021).

Новые возможности 2020 - Новые возможности для изучения языка абаза // Страна Абаза (Электронный ресурс). Доступ: http://www.alashara.org/news/ novyie_vozmojnosti_dlya_ izucheniya_yazyika_abaza (дата обращения 20.06.2020).

Состоялась встреча 2019 - Состоялась встреча Министра образования и науки КЧР Инны Кравченко с проректором Карачаево-Черкесского государственного университета им. У.Д. Алиева. // Министерство образования и науки КЧР (Электронный ресурс). 05.09.2019. Доступ: https://www.minobrkchr.ru/news/detail.php?ID=4360 (дата обращения: 05.03.2019).

Стенограмма 2021 - Стенограмма выступления Путина на заседании Совета по межнациональным отношениям // Президент России (Электронный ресурс). 30.03.2021. Доступ: http://prezident.org/tekst/stenogramma-vystuplenija-putina-na-za sedanii-soveta-pomezhnacionalnym-otnoshenijam-30-03-2021.html (дата обращения: 30.03.2021).

Федеральный закон 1999 - Федеральный закон от 30.04.1999 N 82-Ф3 (ред. от 13.07.2020) «О гарантиях прав коренных малочисленных народов Российской Федерации». Доступ: http:// legalacts.ru/doc/federalnyi-zakon-ot-30041999-n-82-fz-o/ (дата обращения 01.05.2021).

Чирикба 2020 - Чирикба В. Мы должны бросить все силы на сохранение абхазского языка // Всемирный абхазо-абазинский конгресс. Официальный сайт. (Электронный ресурс). 03.02.2020. Доступ: https://abaza.org/vyacheslav-chirikba-my-dolzhny-brosit-vse-sily-nasokhranenie-abkhazskogo-yazyka (дата обращения: 03.02.2020).

Shcherbina, Elena E. and Liana V. Kubanova

\section{Problems of preservation and development of the Abaza language}

DOI: $10.33876 / 2311-0546 / 2021-54-2 / 355-364$

The article is dedicated to the problem of preserving the native language by the Abazins - a recognized small-numbered people in the Russian Federation. The threat of assimilation and language loss has intensified the ethnocultural activities of the Abaza social organizations. The issues of preserving the Abaza language and the convergence of the Abazins with the related Abhazians, including among diasporas in other countries, became priority. On the initiative and with the support of social activists, numerous projects aimed at preserving and developing the Abaza traditional culture are being implemented; it is planned to create a single Abaza-Abkhaz alphabet. The results of sociological surveys conducted in the Karachay-Cherkess Republic over the years revealed a fairly high level of proficiency in the Abaza language, including among young people. A request for studying the native language persists. At the same time, the lack of interest to studying it among some of the respondents is seen as a disturbing trend. However, state language policy, measures taken by social activists and a fairly high level of ethnic identity of the population suggest that the Abaza language will be preserved and continue developing in the nearest future.

Keywords: Abaza language, small-numbered people, ethnic identity, ethnocultural problems

For Citation: Shcherbina E.A., and L.V. Kubanova 2021. Problems of preservation and development of the Abaza language. Herald of Anthropology (Vestnik Antropologii) 2: 355-364. 


\section{Author Info:}

Shcherbina, Elena A. - PhD in political sciences, Deputy-Director, Karachay-Cherkess Institute for Humanitarian Studies under the Government of the Karachay-Cherkess Republic (Cherkessk, RF). E-mail: adenas@list.ru

Kubanova, Liana V. - PhD in political sciences, leading researcher, Karachay-Cherkess Institute for Humanitarian Studies under the Government of the Karachay-Cherkess Republic (Cherkessk, RF). E-mail: lianakubanova@mail.ru

Funding: The research was supported by the Russian Foundation for Basic Research (RFFI, project No. 17-29-09152) 